

\title{
Aspectos morfológicos da infiltração da medula óssea por condições exibindo diferenciação plasmocitária e gamopatia monoclonal
}

\author{
Morphological aspects of bone marrow infiltration by diseases characterized by plasma cell \\ proliferation and monoclonal gamopathy
}

Victor P. Andrade

\section{Introdução}

Nesta atualização discutiremos conceitos e atualizações sobre o envolvimento da medula óssea em quatro condições que podem cursar com gamopatia monoclonal e diferenciação plasmocitária:

1. Linfoma da zona marginal (LZM)

2. Linfoma linfoplasmacítico/Macroglobulinemia de Waldeström (LPL/MW)

3. Gamopatia monoclonal de significado indeterminado (MGUS)

4. Mieloma múltiplo (MM)

As causas de gamopatias monoclonais são a MGUS (55\%-65\%), MM (18\%), Smoldering multiple myeloma (3\%), plasmocitomas isolados ou extraósseos (2\%), LPL/MW (2\%) e LZM/outros linfomas (3\%), amiloidose primária (8\%-12\%), outras causas $(3 \%))^{1,2}$

\section{Gamopatia monoclonal de significado indeterminado}

A gamopatia monoclonal de significado indeterminado (MGUS - Monoclonal gamopathy of underteminated significance) é uma condição pré-maligna caracterizada por:

- Níveis séricos de $\operatorname{IgG}$ ou $\operatorname{IgA}>3 \mathrm{mg} / \mathrm{dL}$ ou

- Proliferação monoclonal limitada de plasmócitos na medula óssea $(<10 \%)$,

-Ausência de lesões de órgãos periféricos, como aqueles observados no mieloma múltiplo (MM). ${ }^{3}$

Esta é a discrasia plasmocitária mais comum, presente em aproximadamente $3 \%$ da população acima de 50 anos, com um risco de evolução para mieloma de $1 \%$ ao ano até os 60 anos e cerca de 5\% após os 70 anos. Muitas vezes os pacientes são assintomáticos. Existem critérios clínicos e laboratoriais para este diagnóstico, mas a biópsia de medula óssea é sempre considerada nos pacientes com esta suspeita diagnóstica a fim de afastar outras causas.

Mais de 90\% dos casos de MGUS tem anormalidades citogenéticas incluindo translocações envolvendo a região 14q32, hiperploidias e deleção do cromossomo 13, comuns ao MM, e, portanto, inúteis na diferenciação diagnóstica, mas com potencial informação prognóstica na avaliação do risco de progressão para MM. ${ }^{4,5}$ As taxas constantes de transformação para MM sugerem uma transformação baseada na hipótese do second-hit como um segundo evento aleatório e não cumulativo, ainda não esclarecido. Mutações do gene

${ }^{1}$ Médico Oncologista. Gerente Médico de Análises Clínicas da Fundação Antônio Prudente Fleury Medicina e Saúde - São Paulo-SP.

Hospital do Câncer/Fundação Antônio Prudente Fleury Medicina e Saúde - São Paulo-SP.

Correspondência: Victor Piana de Andrade

Av. Gen Waldomiro de Lima, 508 - Jabaquara

04344-903 - São Paulo-SP - Brasil

E-mail: victorandrade@fleury.com.br

Doi:10.1590/S1516-84842009005000056 
Ras, Myc, p53, metilações do p16 e outras translocações são descritas em MM e podem corresponder a este segundo evento na tumorigênese. ${ }^{4}$

O ambiente da medula óssea sofre alterações importantes nesta progressão para MM. A mais marcante delas é a angiogênese. Esta mudança está relacionada à detectção de IL-6 e VEGF e é espectral ao longo da progressão, sendo difícil, portanto, ser usada como critério diagnóstico. Entretanto, a elevada angiogênese se correlaciona com doença avançada, índice proliferativo e grau de envolvimento da medula óssea. Esta alteração desencadeou um interesse por estratégias antiangiogênicas no tratamento do $\mathrm{MM}$. $^{6-10}$

Nesta progressão para mieloma múltiplo, alguns pacientes podem ficar por anos em uma condição intermediária, denominada smoldering multiple myeloma (SMM). A distinção entre SMM e MGUS é necessária pelo maior risco de evolução para mieloma (cerca de 10\%-20\% ao ano), muito embora não exista um mecanismo patogenético diferente conhecido. Estes pacientes são assintomáticos, mas podem evoluir com quadro clássico de $\mathrm{MM}$ em um intervalo médio de três anos. ${ }^{4,11}$

Existe ainda uma condição similar, mas com pico sérico de IgM, exibindo os mesmos achados medulares, que caracteriza a smoldering Waldeström's macroglobulinemia (SMW) com risco elevado de progressão para macroglobulinemia de Waldeström (MW) / linfoma linfoplasmacítico (LPL). Neste caso é necessária a ausência de hiperviscosidade, linfadenomatia e hepatoesplenomegalia. ${ }^{4}$

Na medula óssea acometida por MGUS, a presença dos plasmócitos pode ser observada de forma intersticial ou formando grupo de tamanhos variados. O limite de $10 \%$ está baseado na contagem realizada no mielograma, mas a biópsia por agulha é especialmente útil nos casos de infiltração plasmocitária focal. Além disto, não há irregularidade das trabéculas ósseas como observada algumas vezes no MM.

O perfil imuno-histoquímico do MGUS é aquele de plasmócitos bem diferenciados com restrição da imunoglobulina de cadeia leve, ou seja, negativo para CD20, positividade variável para CD79a, positividade para CD138, MUM1, PAX5 e expressão relativa variável de IgKappa e IgLambda.

Há obviamente uma sobreposição com o acometimento focal da medula óssea por MM. A pesquisa imunohistoquímica para CD138 permite quantificar melhor os plasmócitos e avaliar os agregados; entretanto, mesmo associado com IgKappa ou IgLambda, esta não pode ser usada para o diagnóstico diferencial uma vez que ambos são monoclonais. ${ }^{12}$ Usualmente, os plasmócitos no MGUS não têm expressão anômala de CD56, e alguns autores advogam seu uso na diferenciação com o MM, mas outros autores demonstraram que a positividade para CD56 e outras expressões anômalas existem em casos de MGUS e parecem aumentar ao longo do espectro de progressão para MM. ${ }^{13-15}$
As diferenças entre MGUS e MM se baseiam na apresentação clínica-laboratorial e apenas de posse destes dados o diagnóstico é possível.

\section{Mieloma múltiplo}

O MM é uma proliferação plasmocitária letal com envolvimento da medula óssea e tecidos extraósseos com caráter multifocal. Cerca de $90 \%$ dos casos ocorrem em pacientes acima dos 50 anos e a idade mediana é de 70 anos. O MM representa $1 \%$ das neoplasias malignas e $10 \%-15 \%$ das neoplasias hematopoéticas e é responsável por $20 \%$ dos óbitos neste grupo de neoplasias.

Os pacientes são sintomáticos, exibindo fadiga, dor óssea ou outros relacionados aos achados laboratoriais e o diagnóstico requer:

- Pico monoclonal soro (>3 g/dL) ou urina, seja IgM, IgA ou IgG

- 3\% sem pico monoclonal - mieloma não secretor

- Plasmócitos clonais na medula ou plasmocitoma isolado/extraósseo

- Lesão de orgãos alvo: hipercalcemia, insuficiência renal, anemia; lesões ósseas líticas, amiloidose, hiperviscosidade, infecções recorrentes.

O diagnóstico diferencial é amplo e considera nos casos de lesões osteolíticas o hiperparatireoidismo, metástases e outras neoplasias ósseas; nos casos de plasmocitose medular, as inflamações, infecções, doenças autoimunes e hiperreatividades; e, nos casos de gamopatia monoclonal, as doenças imunoproliferativas, carcinomas metastáticos, inflamação/infecção, doenças autoimunes, miopatias/neuropatias, e outras causas como bócio, pólipos colônicos, osteoporose, hiperparatireoidismo, etc.

Os padrões mais comuns de infiltração são o padrão nodular ou difuso com erosão óssea, fibrose e neoformação vascular, mas virtualmente qualquer padrão pode ser observado, inclusive há casos com envolvimento tão focal e discreto que o diagnóstico pode ser dificultado. Deve-se preferir biopsiar sítios de osteólise. O envolvimento extraósseo é sinal de doença avançada.

O padrão morfológico das células pode variar entre plasmócitos bem diferenciados de aspecto normal, células binucleadas, células em anel de sinete ou com citoplasma claro, acúmulos de imunoglobulinas na forma de inclusões nucleares ou cristais citoplasmáticos, células de aspecto monocitoide, pequenas células hipercromáticas, células fusiformes ou histiocitoides (pseudo-Gaucher), plasmablastos ou células polimórficas. ${ }^{16} \mathrm{De}$ fato, a morfologia do MM pode simular desde plasmocitoses reacionais a carcinomas, linfomas e mesmo sarcomas. A presença de células plasmablásticas ou anaplásicas está associada com prognóstico menos favorável e o mieloma anaplásico pode ser usado quando a morfologia imunoblástica/polimórfica for predominante. ${ }^{17,18}$ 
O imunofenótipo está assim descrito:

- Ig citoplasmática + / Ig superficie -

- Kappa ou Lambda

- Positivo

- CD138, CD38, MUM-1

- Raros/Aberrantes

- CD56 ( 75\%), CD52, CD10, CD117, Ciclina D1

- Negativo

- CD20, CD19, CD22

Para além da morfologia plasmablástica, imunoblástica ou polimórfica, da clonalidade de imunoglobulinas de cadeia leve, a expressão aberrante de Ciclina D1, CD56 e CD10 éútil para o diagnóstico diferencial com as plasmocitoses reacionais no contexto adequado.

A pesquisa imuno-histoquímica de plasmócitos na medula óssea pelo anticorpo CD138, combinado com IgKappa e IgLambda, apresenta alta sensibilidade e especificidade na detecção do acometimento focal ou doença residual da medula por mieloma, quando comparado com outros testes, desde que a amostra obtida apresente boa representatividade do parênquima medular, além de apresentar um boa relação de custo-benefício. ${ }^{12,19}$ Embora outros elementos próprios da medula óssea sejam CD138 negativos, alguns carcinomas metastáticos podem apresentar positividade para CD138, em especial adenocarcinomas, e estes podem ter aspecto plasmocitoide. Entretanto, estas neoplasias são positivas para citoceratinas e negativas para IgKappa e IgLambda.

A pesquisa de CD56 por imuno-histoquímica também é um teste útil para diferenciar os plasmócitos com natureza reacional (CD56-) e os de natureza neoplásica (CD56+). ${ }^{13}$ Associações estatísticas foram descritas entre a hiperexpressão de ciclina D1 e o grau de diferenciação plasmocitária e também com a extensão de infiltração da medula óssea nos mielomas. ${ }^{20}$ Estas marcações aberrantes são especialmente úteis nas infiltrações discretas da medula óssea.

Os plasmócitos reacionais tendem a infiltrar a medula isoladamente ou em pequenos agregados perivasculares, enquanto os plasmócitos neoplásicos formam grandes agregados, áreas difusas, mas eventualmente dispõem-se isoladamente.

\section{Linfomas com gamopatia monoclonal e diferenciação plasmocitária}

Os padrões arquiteturais observados nas infiltrações por neoplasias de células B na medula óssea são:

- Difuso: infiltração substitui o parênquima medular

- Intersticial: infiltração permeia o parênquima medular

- Paratrabecular: nódulos linfoides com ampla superfície de contato com trabéculas ósseas

- Nodular: nódulos linfoides sem relação direta com as trabéculas ósseas

- Sinusoidal: células localizadas no interior ou adjacência de sinusoides
Algumas associações entre o tipo de linfoma e o padrão de infiltração da medula óssea são bem descritas, por exemplo, o padrão paratrabecular isolado no linfoma folicular (correspondendo a mais de $90 \%$ dos casos) e o padrão difuso ou nodular no linfoma linfocítico (LLC-B). O padrão sinusoidal foi, no passado, associado ao linfoma da zona marginal (LZM), no entanto, relatos mais recentes têm demonstrado que este padrão é muito inespecífico, raríssimamente acontece como único padrão de infiltração e que a imuno-histoquímica é necessária na identificação fidedigna desta infiltração. ${ }^{21,22}$

A discordância do padrão citológico e arquitetural dos linfomas da medula óssea em relação ao padrão no linfonodo ou baço é bem conhecida da literatura e pode ocorrer de $20 \%-40 \%$ dos casos. Casos difusos no baço ou linfonodo podem ter apresentação nodular na medula e casos com pequenas células na medula não excluem um linfoma de grandes células no linfonodo. Aliás, os casos de linfoma difuso de grandes células com infiltração da medula óssea por células grandes têm um prognóstico pior do que os casos com discordância morfológica e predomínio de células pequenas. ${ }^{23-25}$

Segundo um estudo recente com 450 amostras de medula óssea infiltradas por linfomas, esta discordância morfológica é mais comum nos linfomas difusos de grandes células B (23\%) e no linfoma folicular, que pode não apresentar a morfologia centrocítica clássica $(39 \%)$. Os casos de linfoma da zona marginal apresentaram raramente esta discordância (6\%) e os linfomas linfoplasmacíticos não apresentaram esta divergência morfológica com o sítio primário. $^{21}$

Os patologistas devem estar esclarecidos sobre estes aspectos porque tem havido uma crescente demanda pela classificação dos linfomas em espécimes de medula óssea, a fim de se evitar a retirada cirúrgica de linfonodos ou do baço. O linfoma da zona marginal apresenta uma dificuldade adicional para esta classificação na medula óssea, já que não tem um marcador específico, e o diagnóstico é, pelo menos em parte, dependente da análise arquitetural e do sítio de acometimento.

\section{Linfoma da Zona Marginal (LZM)}

Esta é uma neoplasia indolente, que afeta adultos ou idosos, com predominância do sexo feminino. A gamopatia monoclonal está presente em até um terço dos casos. A célula neoplásica clássica é pequena ou intermediária, com núcleo redondo e citoplasma de moderado a abundante e tem origem em uma célula pós-centro germinativo de memória $\mathrm{IgM}+$. Este tipo celular pode predominar ou estar permeado por linfócitos pequenos ou células plasmocitoides/plasmócitos e células grandes tipo centroblasto ou imunoblasto. Três formas clínicas são reconhecidas: o linfoma da zona marginal extranodal ou linfoma MALT (7,6\% dos linfomas B); linfoma da zona marginal esplênico (LZME; $<1 \%$ dos 
linfomas B) e o linfoma da zona marginal nodal (LZMN; $<1 \%$ dos linfomas B). Casos avançados com comprometimento de linfonodos e baço podem ser impossíveis de subclassificar entre estes tipos de LZM. ${ }^{3}$

Os linfomas MALT têm evidências de hipermutação somática e rearranjo gênico e, em parte, são dependentes do estímulo antigênico para proliferação. O LZME e LZMN podem ser subdividos em grupos com e sem rearranjo do gene da IgH. Não há uma anormalidade citogenética que defina o LZM. ${ }^{3}$

O perfil imunofenotípico dos linfomas da zona marginal demonstra CD19+, CD20+ com restrição de cadeia leve, CD10-, CD5-, CD43 +/- e BCL2+. O LZME é geralmente $\operatorname{IgM}+\operatorname{IgD}+$ enquanto o MALT e LZMN são IgM+IgD-. ${ }^{3}$

De $30 \%$ a $50 \%$ dos linfomas MALT apresentam a translocação t(11:18)(q21:q21) recíproca API-MALT1, e em geral como anormalidade única. Esta translocação não está presente no LZME ou LZMN. O LZME apresenta como alteração mais comum as deleções heterogêneas do cromossomo 7, a t(9:14)(p13:q32), que justapõe os genes da IgH e PAX5. ${ }^{3}$

Os padrões de infiltração são muito variáveis e incluem nodular, paratrabecular e intersticial. $\mathrm{O}$ achado do padrão intrassinusoidal é mais facilmente observado por imunohistoquímica para CD20 ou CD34.

O LZME se manifesta com linfocitose, esplenomegalia, anemia e trombocitopenia. A linfadenopatia periférica é incomum. O LZME acomete a medula com alta frequência (67\%-100\%). Já o linfoma MALT envolve uma variedade de órgãos dos quais o estômago é o mais comum. A maioria dos pacientes tem doença localizada ao diagnóstico e a medula óssea está acometida em apenas 10\%-20\% dos casos. O LZMN se manifesta nos linfonodos periféricos sem esplenomegalia ou apresentação extranodal. Os pacientes acometidos são, em geral, idosos e apresentam linfadenomegalia gereralizada, com $30 \%$ a $40 \%$ de envolvimento da medula óssea. ${ }^{22}$

O linfoma da zona marginal pode infiltrar a medula com uma grande variedade de padrões. Os padrões morfológicos na medula óssea do LZME, do LZMN e do linfoma MALT são muito similares e não é possível a classificação final destes tumores no espécime de medula óssea. A existência de padrões mistos é comum, ocorrendo em $83 \%$ dos casos de LZME e 50\% dos LZMN no estudo de Inamdar e cols. ${ }^{26}$ Franco e cols. analisaram biópsias de medula óssea de 16 pacientes com LZME e encontraram o padrão sinusoidal quase exclusivamente. ${ }^{27}$ Entretanto, em outros estudos este padrão se mostrou inespecífico. Por exemplo, Kent e cols. encontraram o padrão sinusoidal em grande parte dos LZME (83\%), mas também em 55\% dos MALT, sendo inconspícuos no MALT e mais evidentes no LZME. ${ }^{22}$ Outros estudos não identificaram padrão sinusoidal no MALT, ou este foi raro e em menos de 5\% da área de infiltração. Além disto, este padrão foi observado também em linfomas linfoplasmacíticos, linfomas difusos de grandes células B e células do manto, LLC-B e tricoleucemia e não pode ser considerado fidedigno da infiltração por LZM. ${ }^{21,28-31}$

O encontro de centros germinativos clássicos na medula óssea auxilia na distinção entre a natureza benigna ou maligna, mas pode ser visto com baixa frequência nos LZM, especialmente no LZME e linfomas foliculares. Portanto, não deve ser utilizado como critério de exclusão de malignidade. Contudo, em um caso inequivocamente maligno, o encontro de padrão sinusoidal de infiltração e centros germinativos pode sugerir o diagnóstico de LZME. ${ }^{26,32}$

\section{Linfoma linfoplasmacítico}

Esta é uma neoplasia heterogênea e de baixa reproducibilidade diagnóstica, composta por linfócitos pequenos, linfócitos plasmocitoides e plasmócitos, geralmente envolvendo a medula óssea, linfonodos e baço. Este linfoma representa $2 \%$ das neoplasias hematopoéticas e afeta pacientes idosos, com média de 65 anos. O curso clínico é indolente, mas 10\%-15\% apresentam uma evolução mais agressiva. $^{26}$

A morfologia pode variar de formas com maior diferenciação plasmocitária (linfoplasmacítica), uma sugestão apenas de diferenciação plasmocitária (linfoplasmocitoide) ou formas mais atípicas (polimórfico). Esta morfologia está associada com a frequência de alterações citogenéticas, existindo em cerca de $30 \%$ dos casos, sendo $20 \%$ nos linfomas com morfologia linfoplasmacítica e $78 \%$ nos polimorfos, e também com a agressividade biológica, observada em $75 \%$ dos polimorfos e apenas $30 \%$ dos linfoplasmacíticos ou linfoplasmocitoides. O achado citogenético mais comum é a translocação t(9:14)(p13q32), presente em cerca de 50\%, que resulta na fusão IgH/PAX-5 relacionada com o descontrole da proliferação e diferenciação das células B. A transformação para linfoma difuso de grande células ocorre em cerca de $10 \%$ dos casos e está mais associada aos LPL polimórficos e com cariótipos complexos. ${ }^{3,33}$

O pico monoclonal de IgM é demonstrado na maioria dos casos e o perfil imunofenotípico do linfoma linfoplasmacítico é positivo para CD19, CD20, CD22, CD79a, IgM, Igkappa:Lambda $>5: 1$, citoplasmático, marcação variável para CD23, CD38 e CD138 e CD43 e negativo para CD10, CD5, IgG, Ciclina D1, TdT e CD34. ${ }^{34,35}$

A biópsia de medula óssea é mandatória e a biópsia de linfonodo é desejável naqueles com linfonodomegalias superficiais. Setenta e cinco a noventa por cento dos pacientes exibem infiltração medular ao diagnóstico, podendo ser mista, nodular, intersticial ou difusa. Nos casos com medula óssea livre, a obtenção do linfonodo é necessária. ${ }^{3}$

O padrão de infiltração da medula óssea mais comum é o misto, e isoladamente pode ser difuso, intersticial ou nodular, nesta ordem de frequência. Mais frequentemente há um acometimento de mais de $50 \%$ do espaço medular, 
A

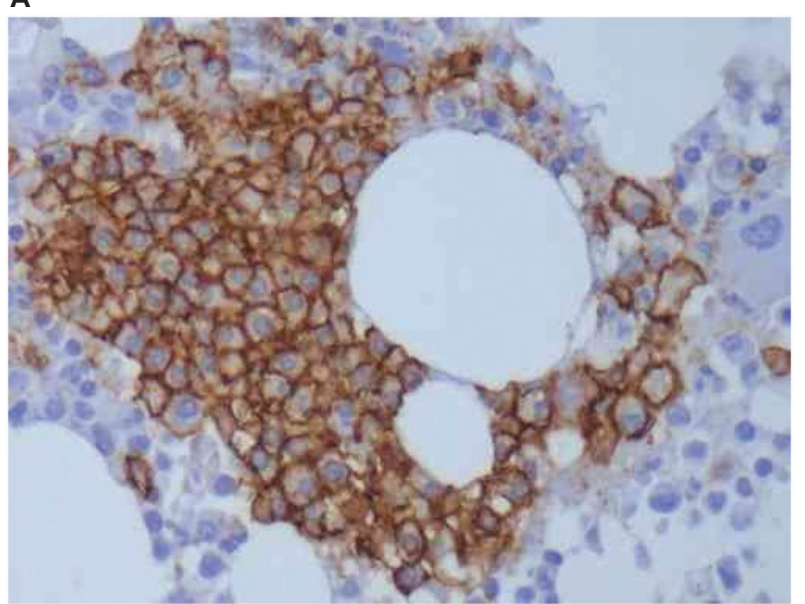

B

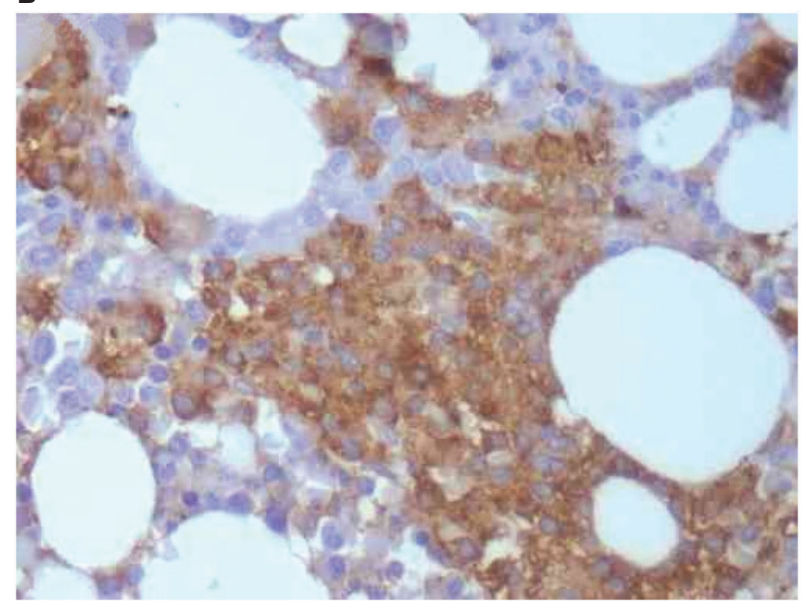

Figura 1. Gamopatia Monoclonal de Significado Indeterminado (MGUS). A: Agregado plasmocitário revelado pela imunomarcação pelo anticorpo CD138 (400x). B: A clonalidade pode ser observada pelo aglomerado de plasmócitos expressando a imunoglobulina de cadeia leve Lambda. IgLambda, 400x.

A B C
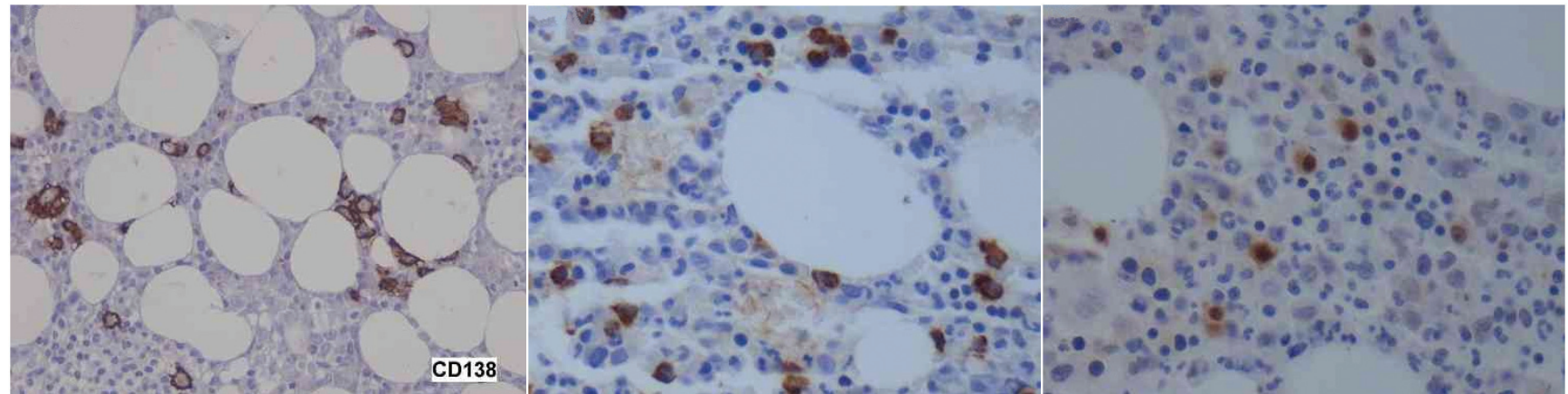

Figura 2. Infiltração focal por Mieloma Múltiplo. Paciente portador de plasmocitoma de clavícula e pico monoclonal sérico de imunoglobulinas. A: Infiltração da medula óssea por plasmócitos isolados ou em pequenos grupos. CD138, 400x. B: Imunopositividade para IgLambda na grande maioria dos plasmócitos. IgLambda, 400x. C: Imunopositividade para CiclinaD1. Ciclina D1, 400x Estas marcacões foram similares às observadas no tumor da clavícula e úteis na diferenciação com plasmocitose reacional

A

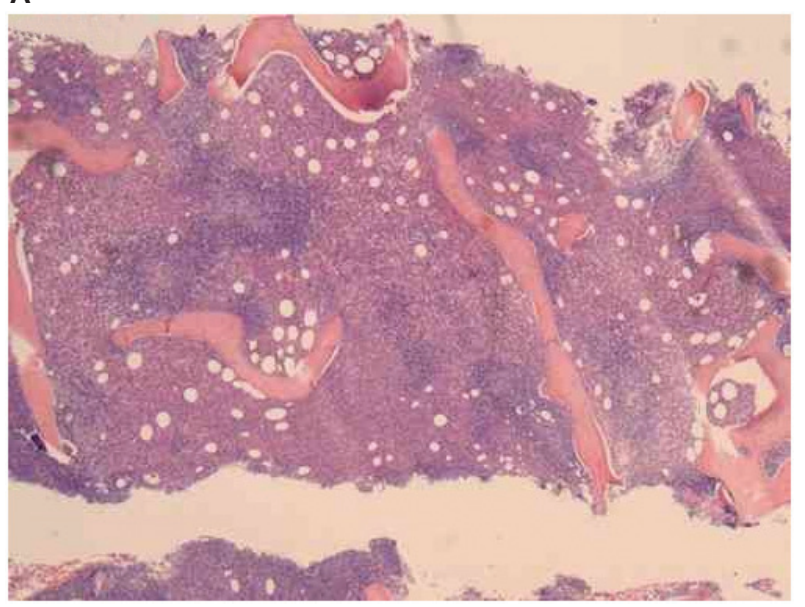

B

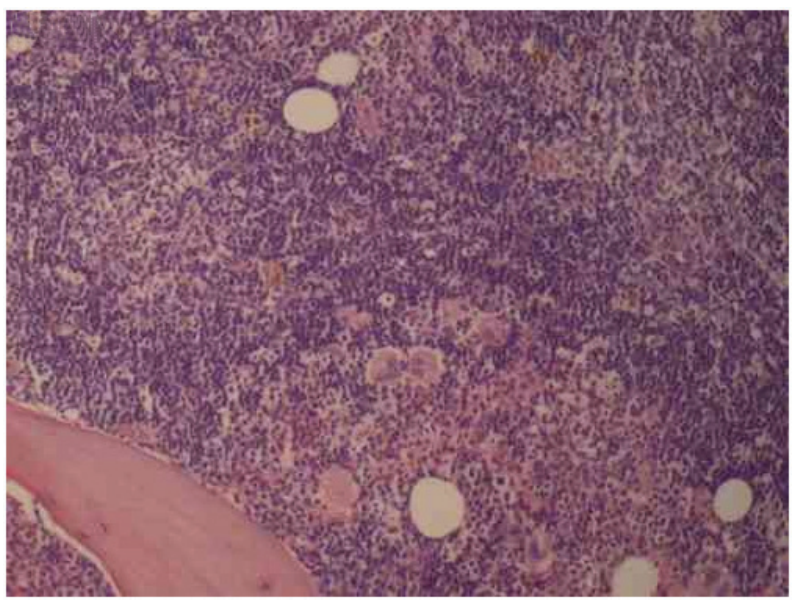

Figura 3. Infiltração da medula óssea por linfoma da zona marginal esplênico. A: Infiltração nodular paratrabecular predominante. Hematoxilina \& eosina, 20x. B: Formação de centros germinativos nos nódulos linfoides. Hematoxilina \& eosina 100x 
A

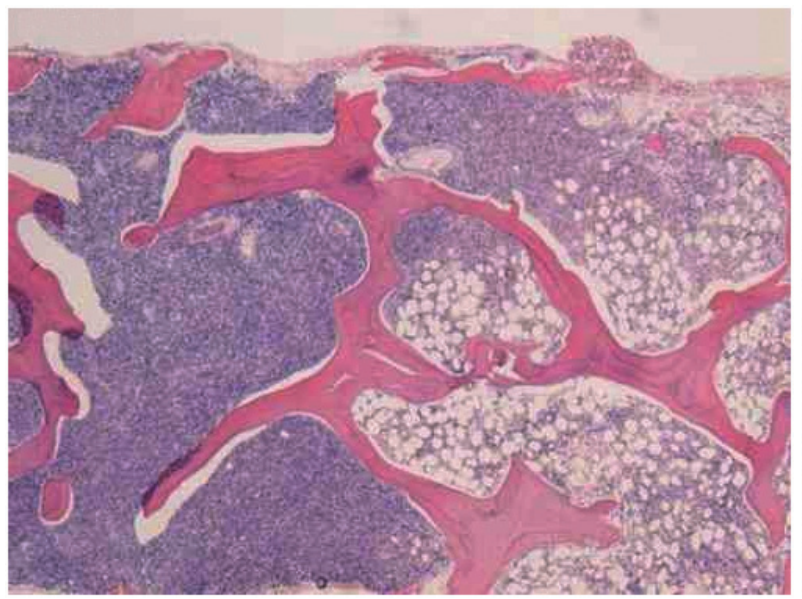

B

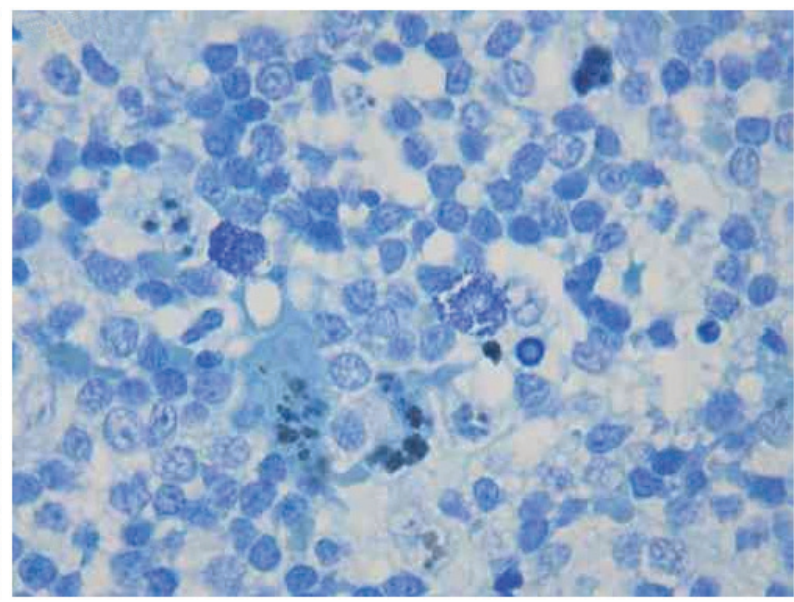

Figura 4. Infiltração da medula óssea por linfoma linfoplasmacítico. A: Extensa área de infiltração difusa da medula óssea, com limite bem marcado do parênquima medular residual. Hematoxilina \& eosina, 40x. B: Frequentes mastócitos e histiócitos com hemossiderina. Giemsa, 400x.

entretanto, o linfoma linfoplasmacítico (LPL) é um dos linfomas que podem apresentar uma infiltração intersticial não detectável ao exame de rotina. ${ }^{21}$ Alguns achados comuns na infiltração medular por LPL são o grande número de mastócitos e macrófagos com hemossiderina entre as células neoplásicas. ${ }^{3}$

\section{Resumo}

- Os casos de gamopatia monoclonal de significado indeterminado, smoldering myeloma, mieloma múltiplo, linfoma linfoplasmacítico e linfoma da zona marginal podem apresentar semelhanças morfológicas e gamopatia monoclonal

- O linfoma da zona marginal, quando infiltra a medula óssea, geralmente o faz com padrões múltiplos, frequentemente com formação de nódulos linfoides com centros germinativos, e o padrão celular é similar ao sítio primário;

- A presença de nódulos linfoides com centros germinativos na medula óssea é um dado a favor da natureza neoplásica; entretanto, quando presente em um caso inequivocamente neoplásico favorece infiltração por linfoma da zona marginal;

- O linfoma linfoplasmacítico infiltra amplamente a medula óssea ( $>50 \%$ da amostra), com padrões múltiplos e predomínio difuso. Mastócitos e macrófagos com hemossiderina são frequentes, e a morfologia celular é similar ao sítio primário;

- O diagnóstico das lesões com diferenciação plasmocitária depende de estreita correlação com aspectos clínicos, radiológicos e laboratoriais;

- A presença de agrupamentos de plasmócitos monoclonais não é necessária e nem suficiente para um diagnóstico de infiltração por mieloma múltiplo

\begin{abstract}
Some lymphoproliferative diseases with plasma cell differentiation and monoclonal gammopathy are challenging to diagnose when dealing with bone marrow biopsies. Knowledge of clinical, morphological, phenotypic and cytogenetic aspects is crucial to establish the correct diagnosis. We describe practical relevant aspects that help in the interpretation of bone marrow biopsies in these situations. Rev. Bras. Hematol. Hemoter. 2009;31(4):273279.
\end{abstract}

Key words: Monoclonal gammopathy; myeloma; lymphoplasmacytic lymphoma; marginal zone lymphoma; bone marrow.

\section{Referências Bibliográficas}

1. Kyle RA, Rajkumar SV. Monoclonal gammopathies of undetermined significance. Hematol Oncol Clin North Am. 1999;13(6):1181202.

2. Kyle RA. Monoclonal gammopathy of undetermined significance and solitary plasmacytoma. Implications for progression to overt multiple myeloma. Hematol Oncol Clin North Am. 1997;11(1):71-87.

3. Swerdlow SH, International Agency for Research on Cancer., World Health Organization. WHO classification of tumours of haematopoietic and lymphoid tissues. 4th ed. Lyon, France: International Agency for Research on Cancer; 2008.

4. Rajkumar SV, Lacy MQ, Kyle RA. Monoclonal gammopathy of undetermined significance and smoldering multiple myeloma. Blood Rev. 2007;21(5):255-65.

5. Kaufmann H, Ackermann J, Odelga V, Sagaster V, Nösslinger T, Pfeilstöcker $\mathrm{M}$, et al. Cytogenetic patterns in multiple myeloma after a phase of preceding MGUS. Eur J Clin Invest. 2008;38 (1):53-60.

6. Alexandrakis MG, Passam FH, Dambaki C, Pappa CA, Stathopoulos EN. The relation between bone marrow angiogenesis and the proliferation index Ki-67 in multiple myeloma. J Clin Pathol. 2004;57(8):856-60. 
7. Alexandrakis MG, Passam FJ, Ganotakis E, Dafnis E, Dambaki C, Konsolas $\mathrm{J}$, et al. Bone marrow microvascular density and angiogenic growth factors in multiple myeloma. Clin Chem Lab Med. 2004;42(10):1122-6.

8. Cibeira MT, Rozman M, Segarra M, Lozano E, Rosiñol L, Cid $\mathrm{MC}$, et al. Bone marrow angiogenesis and angiogenic factors in multiple myeloma treated with novel agents. Cytokine. 2008;41 (3):244-53

9. Bhatti SS, Kumar L, Dinda AK, Dawar R. Prognostic value of bone marrow angiogenesis in multiple myeloma: use of light microscopy as well as computerized image analyzer in the assessment of microvessel density and total vascular area in multiple myeloma and its correlation with various clinical, histological, and laboratory parameters. Am J Hematol. 2006;81(9):649-56.

10. Lin B, Podar K, Gupta D, Tai YT, Li S, Weller E, et al. The vascular endothelial growth factor receptor tyrosine kinase inhibitor PTK787/ZK222584 inhibits growth and migration of multiple myeloma cells in the bone marrow microenvironment. Cancer Res. 2002;62(17):5019-26.

11. Pérez-Persona E, Vidriales MB, Mateo G, García-Sanz R, Mateos $\mathrm{MV}$, de Coca AG, et al. New criteria to identify risk of progression in monoclonal gammopathy of uncertain significance and smoldering multiple myeloma based on multiparameter flow cytometry analysis of bone marrow plasma cells. Blood. 2007; 110(7):2586-92.

12. Ng AP, Wei A, Bhurani D, Chapple P, Feleppa F, Juneja S. The sensitivity of CD138 immunostaining of bone marrow trephine specimens for quantifying marrow involvement in MGUS and myeloma, including samples with a low percentage of plasma cells. Haematologica. 2006;91(7):972-5.

13. Pérez-Andrés M, Almeida J, Martín-Ayuso M, Moro MJ, MartínNuñez G, Galende J, et al. Clonal plasma cells from monoclonal gammopathy of undetermined significance, multiple myeloma and plasma cell leukemia show different expression profiles of molecules involved in the interaction with the immunological bone marrow microenvironment. Leukemia. 2005;19(3):449-55.

14. Martín P, Santón A, Bellas C. Neural cell adhesion molecule expression in plasma cells in bone marrow biopsies and aspirates allows discrimination between multiple myeloma, monoclonal gammopathy of uncertain significance and polyclonal plasmacytosis. Histopathology. 2004;44(4):375-80.

15. Bataille R, Pellat-Deceunynck C, Robillard N, Avet-Loiseau H, Harousseau JL, Moreau P. CD117 (c-kit) is aberrantly expressed in a subset of MGUS and multiple myeloma with unexpectedly good prognosis. Leuk Res. 2008;32(3):379-82.

16. Banerjee SS, Verma S, Shanks JH. Morphological variants of plasma cell tumours. Histopathology. 2004;44(1):2-8.

17. Greipp PR, Leong T, Bennett JM, Gaillard JP, Klein B, Stewart JA, et al. Plasmablastic morphology - an independent prognostic factor with clinical and laboratory correlates: Eastern Cooperative Oncology Group (ECOG) myeloma trial E9486 report by the ECOG Myeloma Laboratory Group. Blood. 1998;91(7):2501-7.

18. Zervas K, Constantinou N, Karakantza M, Tsigalidou-Balla V. Anaplastic myeloma. Leuk Lymphoma. 1995;16(5-6):515-8.

19. Joshi R, Horncastle D, Elderfield K, Lampert I, Rahemtulla A, Naresh KN. Bone marrow trephine combined with immunohistochemistry is superior to bone marrow aspirate in follow-up of myeloma patients. J Clin Pathol. 2008;61(2):213-6.

20. Athanasiou E, Kaloutsi V, Kotoula V, Hytiroglou P, Kostopoulos I, Zervas C, Kalogiannidis $\mathrm{P}$, et al. Cyclin D1 overexpression in multiple myeloma. A morphologic, immunohistochemical, and in situ hybridization study of 71 paraffin-embedded bone marrow biopsy specimens. Am J Clin Pathol. 2001;116(4):535-42.
21. Arber DA, George TI. Bone marrow biopsy involvement by nonHodgkin's lymphoma: frequency of lymphoma types, patterns, blood involvement, and discordance with other sites in 450 specimens. Am J Surg Pathol. 2005;29(12):1549-57.

22. Kent SA, Variakojis D, Peterson LC. Comparative study of marginal zone lymphoma involving bone marrow. Am J Clin Pathol. 2002;117(5):698-708.

23. Robertson LE, Redman JR, Butler JJ, Osborne BM, Velasquez WS, McLaughlin P, et al. Discordant bone marrow involvement in diffuse large-cell lymphoma: a distinct clinical-pathologic entity associated with a continuous risk of relapse. J Clin Oncol. 1991; 9(2):236-42

24. Hodges GF, Lenhardt TM, Cotelingam JD. Bone marrow involvement in large-cell lymphoma. Prognostic implications of discordant disease. Am J Clin Pathol. 1994;101(3):305-11.

25. Yan Y, Chan WC, Weisenburger DD, Anderson JR, Bast MA, Vose $\mathrm{JM}$, et al. Clinical and prognostic significance of bone marrow involvement in patients with diffuse aggressive B-cell lymphoma. J Clin Oncol. 1995;13(6):1336-42.

26. Inamdar KV, Medeiros LJ, Jorgensen JL, Amin HM, Schlette EJ. Bone marrow involvement by marginal zone B-cell lymphomas of different types. Am J Clin Pathol. 2008;129(5):714-22.

27. Franco V, Florena AM, Campesi G. Intrasinusoidal bone marrow infiltration: a possible hallmark of splenic lymphoma. Histopathology. 1996;29(6):571-5.

28. Costes V, Duchayne E, Taib J, Delfour C, Rousset T, Baldet P, et al. Intrasinusoidal bone marrow infiltration: a common growth pattern for different lymphoma subtypes. Br J Haematol. 2002;119(4): 916-22.

29. Pich A, Fraire F, Fornari A, Bonino LD, Godio L, Bortolin P, et al. Intrasinusoidal bone marrow infiltration and splenic marginal zone lymphoma: a quantitative study. Eur J Haematol. 2006;76 (5):392-8

30. Schenka AA, Gascoyne RD, Duchayne E, Delsol G, Brousset P. Prominent intrasinusoidal infiltration of the bone marrow by mantle cell lymphoma. Hum Pathol. 2003;34(8):789-91.

31. Morice WG, Rodriguez FJ, Hoyer JD, Kurtin PJ. Diffuse large Bcell lymphoma with distinctive patterns of splenic and bone marrow involvement: clinicopathologic features of two cases. Mod Pathol. 2005;18(4):495-502.

32. Audouin J, Le Tourneau A, Molina T, Camilleri-Broët S, Adida C, Comperat $\mathrm{E}$, et al. Patterns of bone marrow involvement in 58 patients presenting primary splenic marginal zone lymphoma with or without circulating villous lymphocytes. Br J Haematol. 2003; 122(3):404-12.

33. Mansoor A, Medeiros LJ, Weber DM, Alexanian R, Hayes K, Jones $\mathrm{D}$, et al. Cytogenetic findings in lymphoplasmacytic lymphoma/ Waldenström macroglobulinemia. Chromosomal abnormalities are associated with the polymorphous subtype and an aggressive clinical course. Am J Clin Pathol. 2001;116(4):543-9.

34. Lin P, Medeiros LJ. Lymphoplasmacytic lymphoma/Waldenström macroglobulinemia: an evolving concept. Adv Anat Pathol. 2005; 12(5):246-55

35. Konoplev S, Medeiros LJ, Bueso-Ramos CE, Jorgensen JL, Lin P. Immunophenotypic profile of lymphoplasmacytic lymphoma/ Waldenström macroglobulinemia. Am J Clin Pathol. 2005;124 (3):414-20.

Avaliação: Editor e dois revisores externos

Conflito de interesses: sem conflito de interesse

Recebido: 21/12/2008

Aceito: 16/04/2009 